\title{
Effect of testosterone undecanoate on hematological profiles, blood lipid and viscosity and plasma testosterone level in castrated rabbits
}

\author{
Chen Zhao, MD; ${ }^{*+}$ Du Geon Moon, MD,* Jong Kwan Park, MD*
}

\begin{abstract}
*Department of Urology, Chonbuk National University Medical School, and Institute for Medical Sciences, Chonbuk National University, and Research Institute and CTC for Medical Device of Chonbuk National University Hospital, Jeoniu; 'Department of Urology, Shanghai Institute of Andrology, Renii Hospital, Shanghai Jiao Tong University School of Medicine, Shanghai, China; "Department of Urology, Korea University College of Medicine, Seoul, Korea
\end{abstract}

Cite as: Can Urol Assoc J 2013;7:E221-5. htrp://dx.doi.org/10.5489/cuaj.507

\section{Abstract}

Objective: The association between testosterone replacement therapy and cardiovascular risk remains controversial. Blood viscosity is a known individual risk factor for cardiovascular disease mortality. The objective of the present study was to investigate the effects of the long-acting injectable testosterone undecanoate (TU) on risk factors of cardiovascular disease.

Methods: In total, 24 male New Zealand white rabbits $(2.5 \mathrm{~kg})$ were randomly divided into 3 groups of 8 . Group 1 was used as control. Group 2 was castrated bilaterally and Group 3 was administrated with $6 \mathrm{mg} / \mathrm{kg}$ of TU at day 1 and 6 weeks after castration. Whole blood viscosity, total plasma testosterone, hemoglobin (Hb), hematocrit (Hct), fibrinogen (FBN), total cholesterol (TC), triglyceride (TG), high-density lipoprotein cholesterol (HDL-C) and low-density lipoprotein cholesterol (LDL-C) levels were measured at baseline, 6 weeks and 18 weeks.

Results: In the control group, whole blood viscosity and FBN were significantly increased at 6 and 18 weeks. Castration significantly increased the levels of TC, TG, HDL-C and LDL-C, but decreased $\mathrm{Hct}$ and $\mathrm{Hb}$. In the TU injection group, whole blood viscosity was markedly decreased in all share rates, whereas the FBN level was increased. $\mathrm{Hb}$ and Hct showed a tendency for higher concentration at 6 weeks.

Conclusions: Long-acting injectable TU provides another reliable treatment option for testosterone replacement therapy. Moreover, the patients may receive additional beneficial effect in lowered whole blood viscosity.

\section{Introduction}

Testosterone plays a crucial role in the proper development of male reproductive tissues and in the maintenance of male characteristics. ${ }^{1}$ Testosterone levels decline gradually with age, and testosterone deficiency can cause significant morbidity and substantial reduction in quality of life.

Male hypogonadism, affecting about $30 \%$ of men between the ages of 40 and 79 years, ${ }^{2}$ is a clinical condition in which abnormally low serum testosterone levels are found associated with typical symptoms, including diminished libido and sense of vitality, erectile dysfunction, reduced muscle mass and bone density, depression and anemia. ${ }^{3}$ Although many of these symptoms can be relieved by restoring serum testosterone levels to the normal range, there is considerable controversy about the potential risks of testosterone replacement therapy.

An increasing incidence of hematopoietic disorders is a risk of testosterone use. Testosterone increases erythropoietin production by hypertrophy of renal tissue, particularly in high doses. ${ }^{4}$ Activation of androgen receptors in erythroid cells appears to be necessary for testosterone to develop an erythropoietic effect in the bone marrow. ${ }^{5}$ Drastic elevations of hematocrit $(\mathrm{Hct})$ may be detrimental to patients with underlying coronary, cerebral or peripheral vascular disease by possibly causing an increase in blood viscosity and increased risk of thrombosis. ${ }^{6-8}$ However, no causal relation has been found between higher testosterone levels and cardiovascular disease..$^{9,10}$ On the contrary, recent studies strongly suggest that testosterone has beneficial effects on vascular reactivity in men with coronary artery disease or heart failure failure. ${ }^{11-13}$

Despite this controversy, testosterone supplementation has increased substantially over the last decade due to its wide range of benefits; new testosterone formulations and treatment modalities provide patients with additional options. Nowadays, injectable, transdermal, buccal and oral testosterone formulations are available for clinical use; injectable testosterone is the most preferred and reliable treatment. Testosterone undecanoate (Nebido, Bayer Pharma, Berlin, Germany) is a long-acting testosterone undecanoate (TU) preparation for intramuscular injection (1000 mg). The injections are generally well-tolerated and multidose pharmacokinetics showed that most hypogonadal men would receive adequate replacement with physiological ranges of serum testosterone when administered 6 weeks after the first injection followed by injections every 12 week thereafter. ${ }^{14,15}$

Whole blood viscosity and its role in cardiovascular disease have become an area of increasing research interest. Whole blood viscosity has been independently correlated 
with the major risk factors for cardiovascular disease, and has been revealed to play an important role in the pathogenesis of atherosclerosis. The correlation between testosterone replacement therapy and blood viscosity remains unclear. Only one study has investigated blood viscosity concerning various shear rates. ${ }^{16}$

The objective of our study was to evaluate the effect of long-acting injectable TU on blood viscosity in castrated rabbits over 18 weeks.

\section{Methods}

\section{Animal preparation and blood sampling}

This study was approved by the Animal Care Committee of the Chonbuk National University. In total, 24 male New Zealand white rabbits averaging $2500 \mathrm{~g}$ (3 months old) in weight were used. The rabbits were housed individually with a 12-hour light cycle and room temperature of $20^{\circ} \mathrm{C}$. Animals were fed a commercial rabbit diet ad libitum for 18 weeks. The rabbits were randomly divided into 3 groups of 8 . Group 1 was kept intact as the control. Groups 2 and 3 were bilaterally castrated through $3-\mathrm{cm}$ scrotal incisions, under anesthesia with ketamine $(35 \mathrm{mg} / \mathrm{kg})$ and xylazine ( $5 \mathrm{mg} / \mathrm{kg})$. In Group 3, a physiological level of TU $(6 \mathrm{mg} / \mathrm{kg})$ was intramuscularly injected in the gluteal region followed by a second injection administered 6 weeks later. ${ }^{17}$

Blood samples were obtained via antecubital venipuncture at baseline, 6 and 18 weeks for hematology, including $\mathrm{Hb}, \mathrm{Hct}, \mathrm{FBN}$, total cholesterol (TC), triglyceride (TG), high-density lipoprotein cholesterol (HDL-C), low-density lipoprotein cholesterol (LDL-C), total plasma testosterone and whole blood viscosity. Time of blood sampling was $7 \mathrm{am}$ to $11 \mathrm{am}$; all the blood samples were tested within 3 hours. Hb concentration and Hct levels were measured using standard techniques in a commercial clinical laboratory, as part of complete blood counts.

\section{Measurement of biochemical and hematologic analyses}

Serum concentrations of TC, HDL-C and TG were determined using an AU-600 autoanalyzer (Olympus, Tokyo, Japan) using commercial kits (Randox Laboratories, San Francisco, CA). Serum LDL-C concentration was calculated using the Friedewald formula. FBN concentration was measured with Fibriquik kit (Organon Teknika, Durham, NY) on a trombolyzer analyser.

\section{Measurement of total plasma testosterone}

Blood was collected from rabbits into plastic tubes containing anticoagulant $(0.129 \mathrm{M}$ trisodium citrate) in a bloodto-anti-coagulant $\mathrm{v} / \mathrm{v}$ ratio of 1:9. The citrated blood was immediately centrifuged at $1760 \mathrm{~g}$ for 15 minutes at room temperature to obtain plasma. Total plasma testosterone was measured using the ADVIA Centaur Immunoassay System (Bayer HealthCare, Tarrytown, NY).

\section{Measurement of whole blood viscosity}

Immediately after venipuncture, whole blood viscosity was measured on a viscometer (BIO-VISCO, Jeonju, Korea). In this instrument, blood is maintained at $37^{\circ} \mathrm{C}$ during the entire measurement. The EDTA (ethylenediaminetetracetic acid)preserved blood is injected into the U-shaped disposable capillary assembly to fill one vertical tube. The vertical tubes are filled with blood to unequal heights, thereby providing the pressure gradient for flow in the capillary. The measurement is started by allowing flow to occur, thus altering the heights of blood in the two vertical tubes. Optical sensors detect the two heights as a function of time; the height data are digitized and analyzed immediately by a computer attached to the viscometer, and graphical and tabulated viscosity-shear rate results are generated by the computer. ${ }^{18,19}$

\section{Statistics}

Statistical analyses were performed with SPSS software, 10.01 (SPSS, Chicago, IL). Data were analyzed using oneway analysis of variance (ANOVA) followed by least significant difference (LSD) post-hoc test for multiple comparisons between pairs. Results are reported as mean \pm standard error and differences were considered as significant at $p<0.05$.

\section{Results}

\section{Changes in hematological parameters and total plasma testosterone level}

At baseline, no difference was found among the three groups. In Group 1 (the control group), the FBN level was significantly increased at 6 weeks and 18 weeks when compared with baseline. TC, TG, HDL-C and LDL-C levels were significantly increased in the castration group (Group 2). Castration decreased the FBN level when compared with the control group, but it was still markedly higher than at baseline. TU injection elevated platelet and FBN levels, whereas the concentration of TC was decreased. At 6 weeks, $\mathrm{Hb}$ level in TU group (Group 3) showed a tendency for higher concentration. At 18 weeks, Hct and Hb levels were significantly decreased in Group 2 (Table 1).

\section{Changes in whole blood viscosity}

There was no difference among the three groups in whole blood viscosity at baseline (Fig. 1a). In Group 2, whole blood 
Table 1. Changes in hematological parameters and plasma testosterone

\begin{tabular}{|c|c|c|c|c|c|c|c|c|c|}
\hline \multirow{2}{*}{ Parameters } & \multicolumn{3}{|c|}{ Baseline } & \multicolumn{3}{|c|}{ 6-week } & \multicolumn{3}{|c|}{ 18-week } \\
\hline & Control & Castration & Castration+TU & Control & Castration & Castration+TU & Control & Castration & Castration+TU \\
\hline $\begin{array}{l}\text { Platelet count } \\
(\times 1000 / \mu \mathrm{l})\end{array}$ & $\begin{array}{l}249.25 \\
\pm 16.26\end{array}$ & $242 \pm 24.8$ & $242.17 \pm 22.51$ & $\begin{array}{c}247.38 \\
\pm 36.5\end{array}$ & $\begin{array}{l}240.88 \\
\pm 27.61\end{array}$ & $\begin{array}{c}270.67 \\
\pm 16.63^{\mathrm{ab}}\end{array}$ & $\begin{array}{l}246.17 \\
\pm 23.33\end{array}$ & $\begin{array}{c}256.4 \\
\pm 19.02\end{array}$ & $\begin{array}{c}288.86 \\
\pm 32.72^{\text {ab }}\end{array}$ \\
\hline $\mathrm{Hb}(\mathrm{g} / \mathrm{dl})$ & $\begin{array}{l}11.48 \\
\pm 1.28\end{array}$ & $\begin{array}{l}11.58 \\
\pm 1.1\end{array}$ & $11.48 \pm 1.34$ & $\begin{array}{l}11.45 \\
\pm 2.1\end{array}$ & $\begin{array}{l}12.08 \\
\pm 1.18\end{array}$ & $12.68 \pm 2.33$ & $\begin{array}{l}11.14 \\
\pm 0.65\end{array}$ & $\begin{array}{r}10.63 \\
\pm 1.43\end{array}$ & $11.41 \pm 2.23$ \\
\hline Hct (\%) & $\begin{array}{l}36.36 \\
\pm 3.89\end{array}$ & $\begin{array}{l}36.41 \\
\pm 2.29\end{array}$ & $35.97 \pm 3.88$ & $\begin{array}{l}36.18 \\
\pm 2.93\end{array}$ & $\begin{array}{l}36.33 \\
\pm 2.38\end{array}$ & $38.35 \pm 1.7$ & $\begin{array}{l}35.12 \\
\pm 1.78\end{array}$ & $\begin{array}{l}34.65 \\
\pm 1.92\end{array}$ & $35.93 \pm 2.81$ \\
\hline Fibrinogen (mg/dL) & $\begin{array}{l}172.09 \\
\pm 27.22\end{array}$ & $\begin{array}{c}177.9 \\
\pm 21.24\end{array}$ & $183.97 \pm 32.33$ & $\begin{array}{l}209.86 \\
\pm 24.01^{a}\end{array}$ & $\begin{array}{c}196.1 \\
\pm 24.85^{\mathrm{ab}}\end{array}$ & $\begin{array}{l}214.88 \\
\pm 32.05^{\mathrm{a}}\end{array}$ & $\begin{array}{c}313.6 \\
\pm 26.66^{a}\end{array}$ & $\begin{array}{c}210.55 \\
\pm 19.27^{\mathrm{ab}}\end{array}$ & $\begin{array}{c}268.21 \\
\pm 16.93^{\mathrm{ab}}\end{array}$ \\
\hline $\mathrm{TC}(\mathrm{mg} / \mathrm{dL})$ & $\begin{array}{l}36.48 \\
\pm 7.21\end{array}$ & $\begin{array}{l}35.61 \\
\pm 6.82\end{array}$ & $38.25 \pm 8.11$ & $\begin{array}{l}35.67 \\
\pm 6.65\end{array}$ & $\begin{array}{c}42.74 \\
\pm 5.18^{\mathrm{ab}}\end{array}$ & $34.96 \pm 7.42$ & $\begin{array}{l}38.98 \\
\pm 8.87\end{array}$ & $\begin{array}{c}51.46 \\
\pm 9.47^{\mathrm{ab}}\end{array}$ & $33.75 \pm 6.29^{\mathrm{ab}}$ \\
\hline $\mathrm{TG}(\mathrm{mg} / \mathrm{dL})$ & $\begin{array}{r}76.15 \\
\pm 15.26\end{array}$ & $\begin{array}{c}72.56 \\
\pm 13.47\end{array}$ & $78.52 \pm 17.97$ & $\begin{array}{c}79.41 \\
\pm 20.33\end{array}$ & $\begin{array}{c}86.74 \\
\pm 18.40^{\mathrm{a}}\end{array}$ & $74.55 \pm 22.10$ & $\begin{array}{c}80.15 \\
\pm 19.64\end{array}$ & $\begin{array}{c}94.21 \\
\pm 16.87^{\mathrm{ab}}\end{array}$ & $78.77 \pm 16.58$ \\
\hline HDL-C (mg/dL) & $\begin{array}{l}17.15 \\
\pm 3.21\end{array}$ & $\begin{array}{l}15.42 \\
\pm 4.12\end{array}$ & $16.94 \pm 2.67$ & $\begin{array}{l}18.74 \\
\pm 4.21\end{array}$ & $\begin{array}{c}23.01 \\
\pm 5.22^{\mathrm{ab}}\end{array}$ & $16.74 \pm 3.36$ & $\begin{array}{l}17.40 \\
\pm 2.83\end{array}$ & $\begin{array}{c}28.41 \\
\pm 3.95^{\mathrm{ab}}\end{array}$ & $15.94 \pm 4.10$ \\
\hline LDL-C (mg/dL) & $\begin{array}{c}3.27 \\
\pm 0.72\end{array}$ & $\begin{array}{c}2.96 \\
\pm 0.81\end{array}$ & $3.19 \pm 0.62$ & $\begin{array}{c}3.16 \\
\pm 0.78\end{array}$ & $\begin{array}{l}7.80 \\
\pm 2.9^{\mathrm{ab}}\end{array}$ & $3.38 \pm 1.12$ & $\begin{array}{c}3.61 \\
\pm 0.85\end{array}$ & $\begin{array}{c}11.22 \\
\pm 3.14^{\mathrm{ab}}\end{array}$ & $4.21 \pm 1.62$ \\
\hline $\begin{array}{l}\text { Plasma testosterone } \\
(\mathrm{ng} / \mathrm{mL})\end{array}$ & $\begin{array}{c}0.29 \\
\pm 0.13 \\
\end{array}$ & $\begin{array}{c}0.26 \\
\pm 0.16\end{array}$ & $0.25 \pm 0.15$ & $\begin{array}{c}0.32 \\
\pm 0.18\end{array}$ & - & $0.29 \pm 0.19$ & $0.3 \pm 0.13$ & - & $0.34 \pm 0.17$ \\
\hline
\end{tabular}

Data are expressed as mean \pm standard error of the mean; a: $p<0.05$ intergroup comparison with baseline; b: $p<0.05$ compared with control. The values of control are considered as standard. TU: testosterone undecanoate; Hb:hemoglobin; Hct: hematocrit; TC: total cholesterol; TG: triglyceride; LDL-C: low-density lipoprotein cholesterol; HDL-C: high-density lipoprotein cholesterol.

viscosity values at lower shear rates $(1,2,5$, and $10 /$ second $)$ were significantly lower than control group (Figs. 1b, Fig. 1c). TU injection in this group significantly deceased whole blood viscosity than control group at all shear rates and castration group at low shear rates $(1,2,5$, and 10/second) (Fig. 1b, Fig. 1c). At 6 and 18 weeks, whole blood viscosity was significantly increased at low shear rates $(1,2,5$ and 10/second) in Group 1 (Fig. 2).

\section{Discussion}

Testosterone replacement therapy may be beneficial for men with cardiac disease. In a study of testosterone replacement therapy for men with cardiac disease, 22 men with chronic stable angina treated with transdermal testosterone replacement therapy had greater angina-free exercise tolerance than 24 placebo-treated controls. ${ }^{20}$ Direct injection of physiologic levels of testosterone into the coronary arteries led to an increase in mean coronary artery diameter and blood flow as compared with baseline. ${ }^{21}$

Testosterone plays a role in cardiovascular morbidity and mortality by modulating risk factors of atherosclerosis and vascular function. However, the mechanisms have been unclear.

Blood is a non-Newtonian fluid and its viscosity depends upon many factors like shear rate, Hct, red cell deformability, plasma viscosity and red cell aggregation. The physiological fluidity of blood in the macrocirculation is maintained by high flow forces acting in the large vessels, while the individual determinants of bulk viscosity determine its fluidity in the microcirculation. The rise in plasma viscosity in clinical and nonclinical situations is mainly attributed to a rise in FBN concentration, with a lesser contribution by globulins, TC and TG. These parameters and the Hct value define whole blood viscosity. FBN and plasma viscosity have been positively correlated with age, with a steady rise in FBN values in men and women noted after 30 years of age. ${ }^{22}$

Blood viscosity measurements play an important role in the development and progression of various hematology related diseases, such as cardiovascular diseases, coronary artery disease, stroke and hyperviscosity syndrome. ${ }^{18,23}$ Several viscometers to measure whole blood viscosity have been developed and used to perform the clinical research and to make the standard data of human in clinical trials. The pressure-scanning capillary viscometer measures the viscosity of whole blood over a range of shear rates without the use of anticoagulants. ${ }^{16,19}$ It has been used in some countries, but not available in most clinical laboratories.

In our study, increased FBN was observed in all groups, but in Group 3, the TU injection elevated FBN levels less than in Group 1 (the control group). Although the FBN level was increased in the castration group compared with baseline, it was much lower than in the other groups.

Castration significantly increased TC, TG, HDL-C and LDL-C levels and may be attributed to the decrease of hepatic lipase $(\mathrm{HL})$ and lipoprotein lipase $(\mathrm{LPL})$ activities due to the absence of gonadal hormones. ${ }^{24,25}$ Basaria and colleagues studied the effect of testosterone supplementation in men 65 years old and over with mobility limitations and low serum levels of testosterone. They found that the application of a testosterone gel was associated with an increased risk of cardiovascular adverse events. ${ }^{26}$ However, 


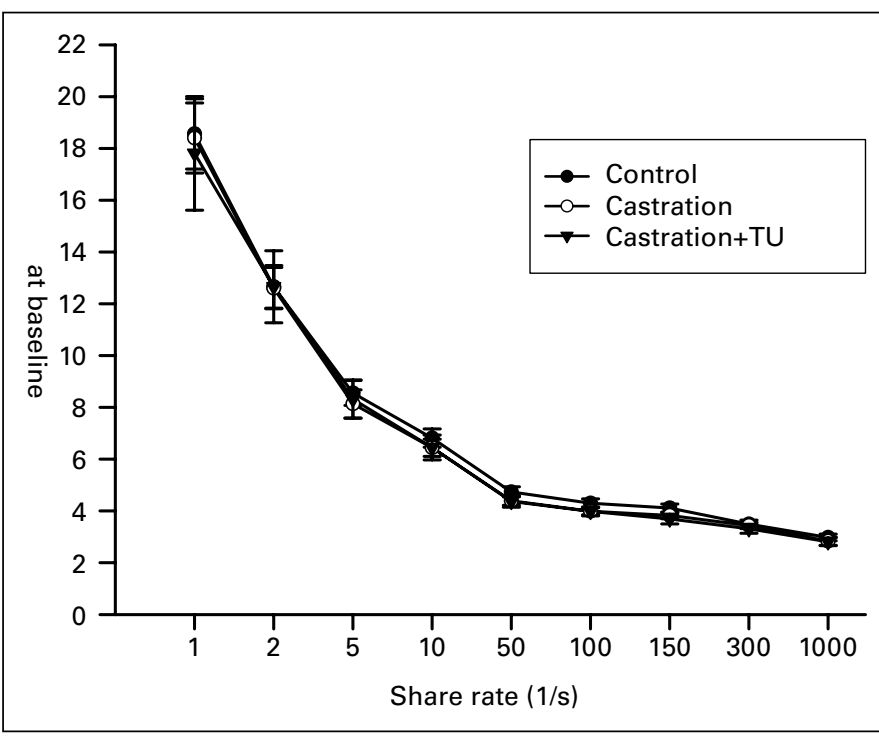

Fig. 1a. Changes of whole blood viscosity in each group at baseline. Each point represents mean \pm standard error; ${ }^{*} p<0.05$ vs. control; $\# p<0.05$ vs. castration group.

meta-analyses of previous trials of testosterone therapy have not shown significant increases in cardiovascular risk. ${ }^{27,28}$ The apparent discrepancies may relate to the differences between the effects of endogenous hormones and those of pharmacologic hormonal therapy, as well as differences in the duration of exposure. However, the lack of elevation in whole blood viscosity in the castration group was due to the decreased Hct and $\mathrm{Hb}$ levels. Testosterone administration did not affect serum TG level, but this parameter was significantly higher in Group 2 (the castration group) than in Group 3 (the testosterone group). This result may be due

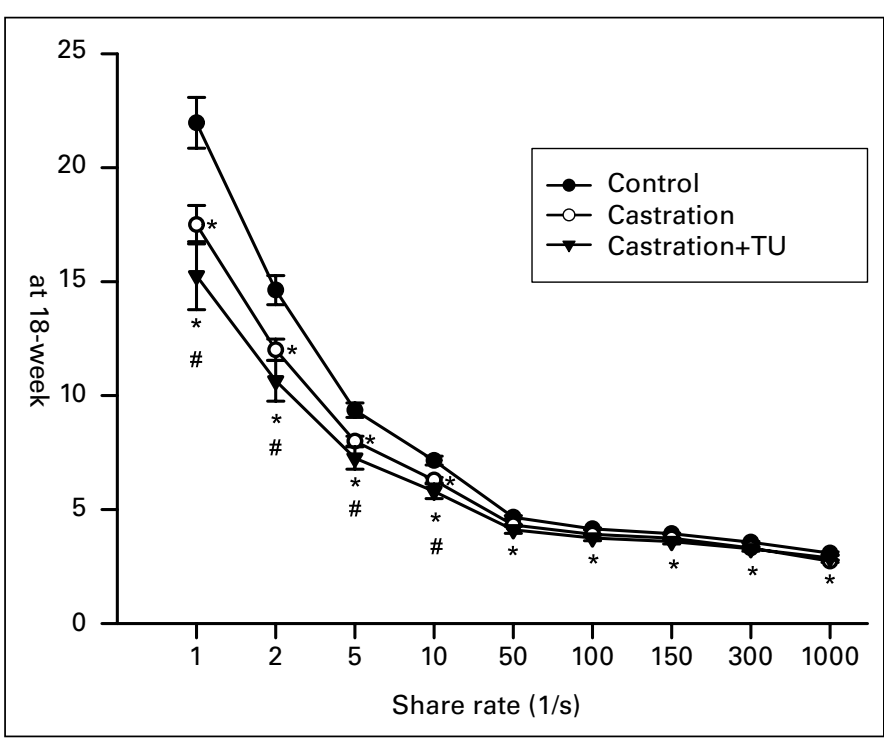

Fig. 1c. Changes of whole blood viscosity in each group at 18 weeks. Each point represents mean \pm standard error; ${ }^{*} p<0.05$ vs. control; $\# p<0.05$ vs. castration group.

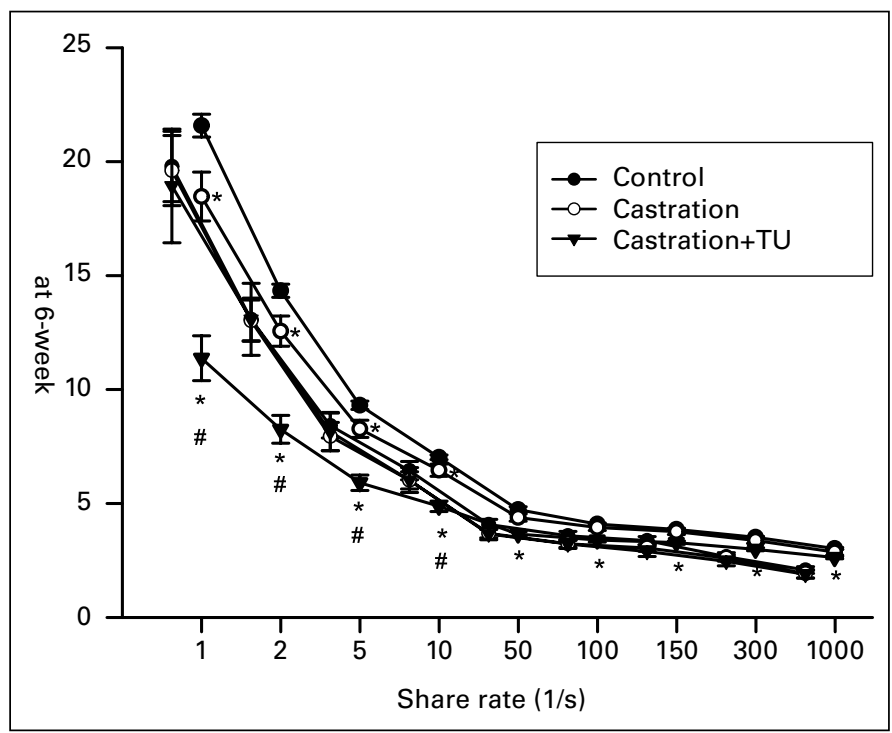

Fig. 1b. Changes of whole blood viscosity in each group at 6 weeks. Each point represents mean \pm standard error; ${ }^{*} p<0.05$ vs. control. $\# p<0.05$ vs. castration group.

to the decreased activity of $\mathrm{LPL}$, which hydrolyses TG in the absence of testosterone. ${ }^{29}$ Testosterone could enhance the platelet count by stimulating the proliferation of erythroid and myeloid progenitors as well. ${ }^{27}$ In Group 3, where a dose of TU was injected a day after castration, $\mathrm{HL}$ and LPL activities did not decrease and there was no "roller coaster" effect on Hct.

FBN, Hct and plasma viscosity are individual risk factors for coronary heart disease mortality. ${ }^{28,30}$ However, the association with whole blood viscosity remains unclear. This is because large-scale epidemiological studies usually mea-

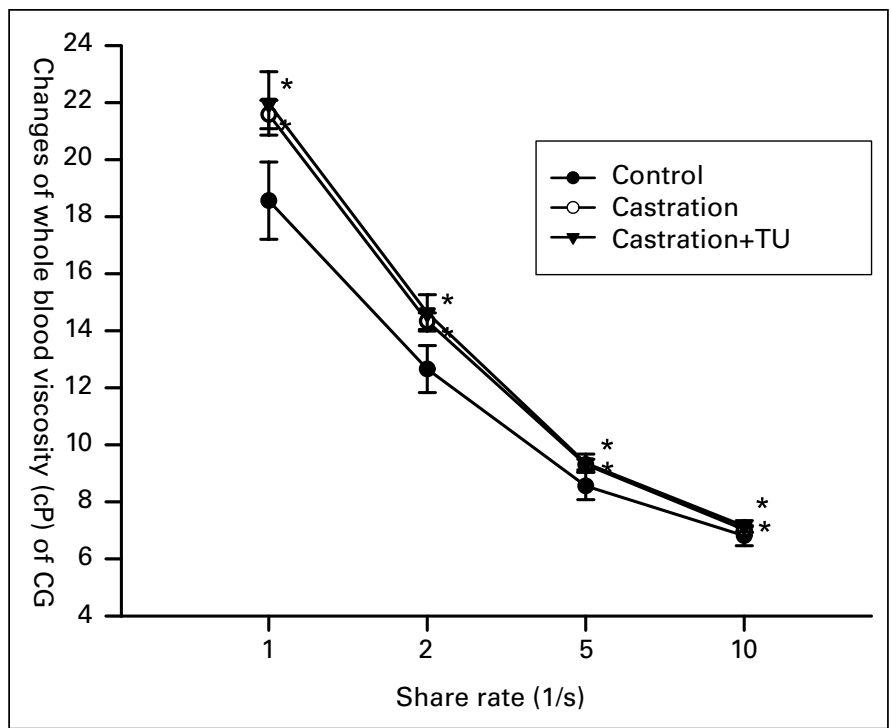

Fig. 2. Changes of whole blood viscosity in the control group. Each point represents mean \pm standard error. CG: control group; ${ }^{*} p<0.05$ vs. baseline. Solid circle is baseline. Open circle is 6 weeks after study. Solid triangle is 18 weeks after study. 
sure plasma viscosity and not whole blood viscosity since whole blood viscosity measurement requires sophisticated apparatus due to the non-Newtonian behavior of blood. ${ }^{31}$ In a study involving 1142 male myocardial infarction patients, a positive relationship was found between plasma viscosity and the severity of coronary heart disease, even after adjusting groups for age, $\mathrm{FBN}$ and use of diuretics. ${ }^{32}$

In our study, increased whole blood viscosity levels in Group 1 (the control group) were correlated to the elevated level of FBN in plasma. Although a lower FBN level was observed in Group 2 (the castration group), higher TC, TG, HDL-C and LDL-C levels might elevate the whole blood viscosity. Decreased blood viscosity in Group 3 (the TU group) was the result of a reduction of TC concentration. Based on these results, TU provides another reliable treatment option for testosterone replacement therapy. Moreover, patients may receive additional benefits in lowing whole blood viscosity. However, the hematological results observed with TU should not be extrapolated to other testosterone preparations.

\section{Conclusion}

TU may have beneficial effects on cardiovascular diseases through the modulation of whole blood viscosity. However, clinical trials are needed to clarify the role of testosterone in the cardiovascular system induced by blood viscosity.

Acknowledgements: This study was supported by a grant of the Korea Healthcare technology R\&D Project, Ministry for Health, Welfare \& Family Affairs, Republic of Korea (A091220).

Competing interests: None declared.

This paper has been peer-reviewed.

\section{References}

1. Winters SJ. Current status of testosterone replacement therapy in men. Arch Fam Med 1999;8:257-63. http://dx.doi.org/10.1001/archfami.8.3.257

2. Rhoden EL, Morgentaler A. Risks of testosterone-replacement therapy and recommendations for monitoring N Engl J Med 2004;350:482-92. http://dx.doi.org/10.1056/NEJMra022251

3. Allan CA, Mclachlan Rl. Age-related changes in testosterone and the role of replacement therapy in older men. Clin Endocrinol (Oxf) 2004;60:653-70. http://dx.doi.org/10.1111/i.1365-2265.2004.02002.x

4. Fried W, Gurney CW. The erythropoietic-stimulating effects of androgens. Ann N Y Acad Sci 1968; 149:35665. http://dx.doi.org/10.1111/j.1749-6632.1968.tb15169.x

5. Malgor LA, Valsecia M, Verges E, et al. Blockade of the in vitro effects of testosterone and erythropoietin on Cfu-E and Bfu-E proliferation by pretreatment of the donor rats with cyproterone and flutamide. Acto Physiol Pharmacol Ther Latinoam 1998;48:99-105.

6. Basaria S, Dobs AS. Risks versus benefits of testosterone therapy in elderly men. Drugs Aging 1999;15:131-42. http://dx.doi.org/10.2165/00002512-199915020-00006

7. Viallard JF, Marit G, Mercie P, et al. Polycythaemia as a complication of transdermal testosterone therapy. Br J Haematol 2000;1 10:237-8. http://dx.doi.org/10.1046/i.1365-2141.2000.02072-3.x

8. Stergiopoulos K, Brennan JJ, Mathews R, et al. Anabolic steroids, acute myocardial infarction and polycythemia: a case report and review of the literature. Vasc Health Risk Manag 2008;4:1475-80.
9. Zmuda JM, Cauley JA, Kriska A, et al. Longitudinal relation between endogenous testosterone and cardiovascular disease risk factors in middle-aged men. A 13-year follow-up of former Multiple Risk Factor Intervention Trial participants. Am J Epidemio/ 1997;146:609-17. http://dx.doi.org/10.1093/ oxfordjournals.aje.0009326

10. Gyllenborg J, Rasmussen SL, Borch-Johnsen K, et al. Cardiovascular risk factors in men: The role of gonadal steroids and sex hormone-binding globulin. Metabolism 2001;50:882-8. http://dx.doi.org/10.1053/ meta.2001.24916

11. Webb CM, Adamson DL, de Zeigler $D$, et al. Effect of acute testosterone on myocardial ischemia in men with coronary artery disease. Am J Cardio 1999;83:437-9. http://dx.doi.org/10.1016/S00029149(98)00880-7

12. Yildirir A, Kabakci G, Can I, et al. Men with coronary artery disease have lower levels of androgens than men with normal coronary angiograms. Eur Heart J 2001;22:612-3. http://dx.doi.org/10.1053/ euhi.2000.2365

13. Aukrust $\mathrm{P}$, Ueland $\mathrm{T}$, Gullestad $\mathrm{L}$, et al. Testosterone: a novel therapeutic approach in chronic heart failure? J Am Coll Cardiol 2009;54:928-9. http://dx.doi.org/10.1016/i.jacc.2009.05.039

14. Behre HM, Abshagen K, Oettel $M$, et al. Intramuscular injection of testosterone undecanoate for the treatment of male hypogonadism: phase I studies. Eur J Endocrinol 1999;140:414-9. http://dx.doi. org/10.1530/eje.0.1400414

15. Schubert $M$, Minnemann T, Hubler D, et al. Intramuscular testosterone undecanoate: pharmacokinetic aspects of a novel testosterone formulation during long-term treatment of men with hypogonadism. J Clin Endocrinol Metab 2004;89:5429-34. http://dx.doi.org/10.1210/ic.2004-0897

16. Jeong SK, Cho YI, Duey M, et al. Cardiovascular risks of anemia correction with erythrocyte stimulating agents: should blood viscosity be monitored for risk assessment? Cardiovasc Drugs Ther 2010;24:151-60. http://dx.doi.org/10.1007/s10557-010-6239-7

17. Gui QF, XU ZR, Lou YM, et al. Effect of testosterone on neointimal proliferation and blood lipids after balloon-induced aorta injury in rabbits. Zhejiang Da Xue Xue Bao Yi Xue Ban 2008;37:393-8.

18. Alexy T, Wenby RB, Pais E, et al. An automated tube-type blood viscometer: validation studies. Biorheology 2005;42:237-47.

19. Shin S, Ku Y, Park MS, et al. Measurement of blood viscosity using a pressure-scanning capillary viscometer. Clin Hemorheol Microcirc 2004;30:467-70.

20. English KM, Steeds RP, Jones TH, et al. Low-dose transdermal testosterone therapy improves angina threshold in men with chronic stable angina: A randomized, double-blind, placebo-controlled study. Circulation 2000;102:1906-11. http://dx.doi.org/10.1161/01.(IR.102.16.1906

21. Webb CM, McNeill JG, Hayward CS, et al. Effects of testosterone on coronary vasomotor regulation in men with coronary heart disease. Circulation 1999;100:1690-6. http://dx.doi.org/10.1161/01. CIR. 100.16 .1690

22. Tarallo P, Henny J, Gueguen R, et al. Reference limits of plasma fibrinogen. Eur J Clin Chem Clin Biochem 1992;30:745-51.

23. Rosencranz R, Bogen SA. Clinical Laboratory Measurement of Serum, Plasma, and Blood Viscosity. Am J Clin Pathol 2006;125:S78-S86.

24. Tikkanen MJ, Nikkila EA. Regulation of hepatic lipase and serum lipoproteins by sex steroids. Am Heart J 1987;113:562-7. http://dx.doi.org/10.1016/0002-8703(87)90633-8

25. Bai LS, Kurup PA. Testosterone \& lipid metabolism in rabbits. Indian J Exp Biol 1976;14:705-7.

26. Basaria S, Coviello AD, Travison TG, et al. Adverse events associated with testosterone administration. $N$ Engl J Med 2010;363:109-22. http://dx.doi.org/10.1056/NEJMoa1000485

27. Beran $M$, Spitzer $G$, Verma DS. Testosterone and synthetic and androgens improve the in vitro survival of human marrow progenitor cells in serum-free suspension cultures. J Lab Clin Med 1982;99:247-53.

28. Danesh J, Collins R, Peto R, et al. Hematocrit, viscosity, erythrocyte sedimentation rate: meta-analyses of prospective studies of coronary heart disease. Eur Heart J2000;21:515-20. http://dx.doi.org/10.1053/ euhi.1999.1699

29. Aydilek N, Aksakal M. Effects of testosterone on lipid peroxidation, lipid profiles and some coagulation parameters in rabbits. J Vet Med A Physiol Pathol Clin Med 2005;52:436-9. http://dx.doi.org/10.1111/ j.1439-0442.2005.00764.x

30. Ercan M, Konukoglu D, Erdem Yeşim T. Association of plasma viscosity with cardiovascular risk factors in obesity: an old marker, a new insight. Clin Hemorheol Microcirc 2006;35:441-6.

31. Kenyeres P, Juricskay I, Tarsoly P, et al. Low hematocrit per blood viscosity ratio as a mortality risk factor in coronary heart disease. Clin Hemorheol Microcirc 2008;38:51-6.

32. Junker R, Heinrich J, Ulbrich $H$, et al. Relationship between plasma viscosity and the severity of coronary heart disease. Arterioscler Thromb Vasc Biol 1998;18:870-5. http://dx.doi.org/10.1161/01. ATV.18.6.870

Correspondence: Dr. Jong Kwan Park, Department of Urology, Medical School, Chonbuk National University, Jeonju, Korea; fax: 82-63-250-1564; rain@chonbuk.ac.kr 